Artigo original

Hegemonia - Revista Eletrônica de Relações Internacionais do Centro Universitário Unieuro

ISSN: $1809-1261$

UNIEURO, Brasília, número 10, 2012, pp. 92-126.

Recebido em: 30/4/2012

Revisado em: 22/5/2012

Aprovado em: 4/6/2012

\title{
Antártica e as formas de cooperação que ocorrem no continente envolvendo o Meio Ambiente
}

FRANCO, Laís Ferreira ${ }^{1}$

Resumo: $O$ artigo irá abordar sobre o continente antártico e as formas de cooperação Internacional que ocorrem naquele continente, no âmbito do meio ambiente. Definirá a importância do local para pesquisas e como foi considerado bem comum da humanidade. Abordará ainda sobre a origem do Tratado da Antártica e sobre o Protocolo de Madri, sendo este um dos mais importantes sobre meio ambiente já discutido no continente antártico.

Palavras-chave: Cooperação. Meio Ambiente. Tratado da Antártica. Protocolo de Madri.

Abstract: The article will address over the Antarctic continent and forms of international cooperation taking place on that continent, within the environment. It will set the importance of the location for research and was nominated World Heritage. It will also address on the origin of the Antarctic Treaty and on the Madrid Protocol, which is one of the most important involving the environment.

Key-words: Environment. Antartic Treaty. Madri Protocol.

1 Bacharel em Relações Internacionais pelo Centro Universitário Unieuro. 
Artigo original

Hegemonia - Revista Eletrônica de Relações Internacionais do Centro Universitário Unieuro

ISSN: $1809-1261$

UNIEURO, Brasília, número 10, 2012, pp. 92-126.

\section{INTRODUÇÃO}

A região polar antártica, no extremo sul do planeta, é formada pelo continente e pelo oceano Austral. No total, a região compreende 45,6 milhões de km2 onde já foram registradas temperaturas de $89^{\circ} \mathrm{C}$ e ventos de $327 \mathrm{~km} / \mathrm{h}^{2}$. O continente antártico é o único sem divisão geopolítica e seus 14 milhões de quilômetros quadrados representam cerca de $10 \%$ da terra emersa. Centrado aproximadamente no Pólo Sul Geográfico, é o lugar mais frio do mundo e $99,6 \%$ de sua área é coberta por gelo, com espessura média de $1.820 \mathrm{~m}$. É totalmente rodeado pelo oceano Austral, que no inverno pode ser coberto por uma fina camada de gelo marinho. Apenas no verão uma estreita faixa de terra, próxima ao mar, fica sem gelo ou neve. ${ }^{2}$

Tanto gelo equivale $80 \%$ da água doce do planeta, no entanto, - lugar é um impressionantemente deserto, com precipitações inferiores às do Saara. O continente é circundado por um tempestuoso oceano completamente livre de barreiras naturais, um mar sem fim onde ventos de $100 \mathrm{~km} / \mathrm{h}$ são considerados comuns, segundo Felipe Rodrigues Gomes Ferreira, autor do livro O sistema do

\footnotetext{
2 Retirado do sitio do Ministério da Ciência e Tecnologia do Brasil.
} 
Artigo original

Hegemonia - Revista Eletrônica de Relações Internacionais do Centro Universitário Unieuro

ISSN: $1809-1261$

UNIEURO, Brasília, número 10, 2012, pp. 92-126.

Tratado da Antártica: Evolução do Regime e seu Impacto na Política Externa Brasileira.

Esse local era desconhecido da humanidade até o século XVIII e permaneceu praticamente intocado até o século XX. Presentemente só o continente antártico continua tendo condições comparáveis às do passado, o que faz daquela região um imenso laboratório cientifico. No século passado, o interesse pela Antártica verifica-se no envio de diversas expedições cientificas e na realização do Primeiro Ano Polar $(1882-1883)^{3}$.

O artigo tem por objetivo verificar as primeiras formas de cooperação ocorridas no continente, como os Anos Polares, o Ano Geofísico Internacional ate o Tratado de Washington. Logo depois o artigo mostra a evolução do Tratado de Washington ate chegar ao Tratado da Antártica. ${ }^{4}$ Depois é mostrado à importância do continente e seus recursos naturais, como esses por sua vez influenciam decisões ou são afetadas pela mesma, em todo o mundo. É mostrado como o Protocolo de Madri complementa o STA, e o ajuda a manter a

3 O Ano Polar foi a primeira demonstração Internacional, que se preocupava efetivamente com as regiões polares, no entanto, sua primeira reunião só ocorreu anos depois. O idealizador foi o Australiano Carl Weyprecht.

$4 \quad$ Ver anexos. 
Artigo original

Hegemonia - Revista Eletrônica de Relações Internacionais do Centro Universitário Unieuro

ISSN: $1809-1261$

UNIEURO, Brasília, número 10, 2012, pp. 92-126.

ordem no continente. E por fim, algumas considerações finais sobre o tratado e algumas previsões para o futuro do mesmo.

\section{PRIMEIRAS FORMAS DE COOPERAÇÃO NO CONTINENTE}

A partir do século $X X$, diversas nações começaram a participar efetivamente, mediante instalações de bases e organização de programas científicos, das questões austrais. Entre esses programas, se destaca a instituição do Ano geofísico Internacional (1957 - 1958) e a celebração do Tratado Antártico (1959). SILVA, 1987, p. 6.

Os interesses pelos aspectos geofísicos da Terra antártica, levou os cientistas do Século XIX, a organizar os Anos Polares. Induzidas pelos institutos científicos europeus, dez nações formaram o primeiro corpo internacional de especialistas e de pesquisas, como trabalho de equipe e objetivos demarcados, de acordo com Péricles Azambuja no livro Antártida: História e Geopolítica. Assim em 1884/5, ocorreu o primeiro Ano Polar, quase meio século depois o segundo Ano Polar e finalmente o chegou-se ao terceiro Ano Polar, que ficou conhecido como o Ano Geofísico Internacional (AGI). 
Artigo original

Hegemonia - Revista Eletrônica de Relações Internacionais do Centro Universitário Unieuro

ISSN: $1809-1261$

UNIEURO, Brasília, número 10, 2012, pp. 92-126.

O Ano Geofísico Internacional, celebrado por ocasião da máxima atividade das manchas solares, entre $1^{0}$ de julho de 1957 e 31 de dezembro de 1958, foi o pontapé inicial aos estudos geográficos, climáticos e magnéticos sobre a Antártica. Estados Unidos, União Soviética, França, Reino Unido, Argentina, Chile, Austrália, Nova Zelândia, Bélgica, Noruega e Japão foram os países que contribuíram para esse esforço científico, construindo um total de 50 estações de pesquisas na Antartica, totalizando mais de 5000 pessoas no continente. Segundo Ferreira $^{5}$, EUA e URSS estabeleceram sete estações cada. Para organizar os programas científicos naquele continente, o Internacional Council of Scientific Unions, ICSU criou o Committee on Antartic Research, SCAR, que até hoje coordena, em nível internacional, as pesquisas cientificas no continente e possui um importante papel no STA (Sistema Tratado da Antártica). É importante lembrar o caráter privado do ICSU e do SCAR. Seus membros são representantes acadêmicos, não de seus respectivos governos.

Ferreira ainda mostra que em Maio foi enviado aos 11 países que estabeleceram estações antárticas durante o AGI, uma proposta de realização de uma conferência em Washington, para a criação de

5 FERREIRA, 2009, P.39. 
Artigo original

Hegemonia - Revista Eletrônica de Relações Internacionais do Centro Universitário Unieuro

ISSN: 1809-1261

UNIEURO, Brasília, número 10, 2012, pp. 92-126.

um regime internacional para Antártica. O convite retomava os pontos centrais da Declaração de Escudero $^{6}$ que continha alguns princípios do que viria a ser o Tratado da Antártica.

O Tratado da Antártica7, que entrou em vigor em 23 de Junho de 1961 e foi ratificado por 12 países com atividades científicas na Antártica, teve como propósito que a região pudesse ser usada somente pra fins pacíficos e para realização de pesquisa científica. Segundo Silva, o interesse demonstrado pela posição do continente nas relações internacionais comprova a existência de uma nova força no cenário mundial, a qual é resultado de uma nova experiência de convivência internacional, convivência essa que visa desenvolver ramos da ciência.

A cooperação cientifica se mostrou a chave para a solução dos conflitos envolvendo questões territoriais naquela região. Maior exemplo dessa cooperação foi entre os países que reivindicam território no continente, a questão da soberania foi literalmente "congelado" por meio do tratado da Antártica, esse por sua vez foi ratificado por 12 Estados com atividades cientificas no país, com o propósito de que a região pudesse ser usada somente para fins

$6 \quad$ Em 1948 o Chile apresenta a Declaração de Escudero, na qual propunha uma pausa de 5 anos na discussões a cerca da soberania sobre a Antártica.

$7 \quad$ Ver o Tratado em anexo, a). 
Artigo original

Hegemonia - Revista Eletrônica de Relações Internacionais do Centro Universitário Unieuro

ISSN: $1809-1261$

UNIEURO, Brasília, número 10, 2012, pp. 92-126.

pacíficos e para a realização de pesquisa cientifica. A pesquisa cientifica, por sua vez, se consagrou como principal atividade humana na Antártica, que só foi possível graças à cooperação internacional proporcionada pelo tratado e atualmente caso não houvesse essa cooperação, dificilmente teríamos como avaliar fenômenos climáticos globais da forma apropriada

A Antártica é de fato uma cooperação Internacional bem sucedida, mesmo com a existência de valores e crença de diferentes atores. A percepção da realidade e atribuição de causa e efeito, comuns aos atores são determinantes na formação de regimes, apesar da incerteza e dificuldade dos atores de antever como operação do regime ou ausência dele poderá afetar seus interesses ao longo do tempo, isso incentiva os atores a buscarem arranjos institucionais mais flexíveis, que sejam aceitáveis para todos.

O tRATAdo de WAShington e A EVOlução do SISTEMA ANTARTICO

O evento que colocou a Antártica como cenário do maior projeto cientifico de toda historia da humanidade foi a realização do Ano geofísico Internacional, onde países implementaram programas de pesquisas cientificas sem precedentes no continente Austral." (SILVA, 1987). 
Artigo original

Hegemonia - Revista Eletrônica de Relações Internacionais do Centro Universitário Unieuro

ISSN: $1809-1261$

UNIEURO, Brasília, número 10, 2012, pp. 92-126.

De fato, ao final do AGI, os participantes sentiram a necessidade de dar continuidade ao clima de cooperação cientifica subsistente nesses programas. Buscaram dessa forma, primeiro entendimento pelos canais diplomáticos, entendimentos entre si e também sobre pontos de interesses em comum naquela região. 0 resultado de tais entendimentos foi concretizado com o Tratado da Antártica, conhecido também por Tratado de Washington.

O Tratado Antártico apresenta a particularidade de ter sido o primeiro acordo internacional a considerar temas inéditos à época, classificando como o sexto continente de primeira zona de paz do mundo, primeiro laboratório cientifico aberto à humanidade, primeira reserva ecológica mundial e primeira área desnuclearizada.

Apesar de ser o principal instrumento jurídico a reger questões antárticas, o tratado dispõe de um importante e útil mecanismo: a realização periódicas de reuniões de consulta (arto $9, \S 1^{\circ}$ ), o qual permite aprimorá-lo e adéqua-lo às realidades contemporâneas. O resultado desses encontros entre os Estados - Membros vêm em forma de recomendações. Estas integram o ordenamento jurídico antártico, ao lado das convenções dos recursos vivos marinhos 
Artigo original

Hegemonia - Revista Eletrônica de Relações Internacionais do Centro Universitário Unieuro

ISSN: $1809-1261$

UNIEURO, Brasília, número 10, 2012, pp. 92-126.

antárticos. (BAKKER; 1984. P.8) Denomina-se o Sistema do Tratado Antártico a todo esse conjunto legal.

O documento assinado em Washington foi considerado por muitos analistas da época, como um primor da "ambigüidade criativa", por não ter solução à questão territorial e não prevê providências para a exploração de recursos naturais. No entanto como aponta Ferreira, essas críticas partem do pressuposto que a questão territorial pode ser resolvida satisfatoriamente. ${ }^{8} \mathrm{~A}$ possibilidade de exploração de recursos naturais estava presente nas mentes de todos na conferência, mas qualquer referência a esse tema necessariamente levantaria novamente o imbróglio territorial. Apesar de estar longe de ser um instrumento jurídico perfeito, o tratado provou sua efetividade e legitimidade ao longo de seus 50 anos de existência, como mecanismo adequado para abrigar uma série de regimes mais específicos sobre diferentes temas.

O tratado estabelece as bases e pilares de seu funcionamento e de seu sistema orgânico nas chamadas Reuniões Consultivas, de que participam os membros originários e os aderentes-ativos, enquanto realizarem atividades cientificas na área espacial convencionada,

8 FERREIRA, 2009, P. 47. 
Artigo original

Hegemonia - Revista Eletrônica de Relações Internacionais do Centro Universitário Unieuro

ISSN: 1809-1261

UNIEURO, Brasília, número 10, 2012, pp. 92-126.

ficando vedado o acesso aos aderentes que não efetuarem atividades configuradas no Artigo IX.

"Os representantes das Partes Contratantes, mencionadas no preâmbulo deste Tratado, reunir-se-ão na cidade de Camberra, dentro de dois meses após a entrada em vigor do Tratado, e daí por diante sucessivamente em datas e lugares convenientes, para o propósito de intercambiarem informações, consultarem-se sobre matéria de interesse comum pertinente à Antártida e formularem, considerarem e recomendarem a seus Governos medidas concretizadoras dos princípios e objetivos do Tratado."

Nessas reuniões consultivas, foram adotados resoluções de caráter regulamentário, abrangendo inúmeros aspectos da atividade antártica, provendo normas e estabelecendo recomendações e critérios objetivando o cuidado de seus recursos vivos, considerados da máxima importância econômica e alimentar para a humanidade como base de subsistência.

\section{RECURSOS NATURAIS DA ANTARTICA E SUA IMPORTÂNCIA}

O Tratado não faz menção ao uso de recursos naturais, a não ser por uma breve nota mencionando preservação e conservação de recursos naturais vivos (art.IX, 1,f), porém a possibilidade de exploração para fins econômicos existia na mente dos negociadores, mas trazer o assunto à tona, especialmente a exploração de recursos 
Artigo original

Hegemonia - Revista Eletrônica de Relações Internacionais do Centro Universitário Unieuro

ISSN: 1809-1261

UNIEURO, Brasília, número 10, 2012, pp. 92-126.

minerais, poderia interferir em qualquer acordo referente às questões territoriais.

Azambuja no livro Antártida: História e geopolítica mostrava as primeiras formas de ação de preservação do meio ambiente antártico:

"Neste aspecto da fauna e flora antárticas e subantárticas, a Reunião Consultiva de Bruxelas, 1964, estabeleceu critérios de proteção dentro do que denominou "Aréa Especial de Conservação", abrangendo o espaço jurídico do Tratado. Posteriormente, foi criada uma Convenção para a conservação das focas polares austrais, incluída no contexto do Estatuto, quando então este foram vinculadas a zona de Pack - ice ( gelo compacto) especificamente no que se refere á proteção dos penípedes, uma vez que o mar alto não é abrangido pelo Protocolo Internacional. Destes animais, $80 \%$ vivem sobre estes tipos de gelo, e portanto, sem essa convenção protetora estariam ameaçados de extermínio."

Por sua posição geográfica e quadro climático único, o continente austral oferece condições de pesquisa que não podem ser encontradas em lugar nenhum do planeta, tampouco reproduzidas. Um dos campos de pesquisa é o estudo genético da biodiversidade antártica. A região apresenta um ecossistema bastante diversificado, mas sua cadeia alimentar tem poucos estágios, fornecendo ótimas condições para estudar a evolução natural e a relação entre genética

$9 \quad$ AZAMBUJA, 1994, P.263. 
Artigo original

Hegemonia - Revista Eletrônica de Relações Internacionais do Centro Universitário Unieuro

ISSN: 1809-1261

UNIEURO, Brasília, número 10, 2012, pp. 92-126.

e meio ambiente, além da adaptação de seres vivos a condições extremas. ${ }^{10}$

Tudo o que acontece por lá tem conseqüências no resto do planeta, assim como tudo o que é feito no resto do mundo acaba se refletindo na Antártida. Por isso, o continente é um dos mais importantes centros de pesquisa sobre o meioambiente existente, sendo base científica de diversos países. ${ }^{11}$

É, no entanto, no estudo do clima que estão às maiores implicações da pesquisa cientifica realizada na Antártica. Nenhuma previsão meteorológica de longo prazo pode ser feita sem dados da Antártica, tampouco qualquer modelo global sobre clima pode ignorar sua influência no resto do planeta, fenômenos como o El Niño não podem ser completamente estudados, a intensidade de estações chuvosas ou secas nas regiões tropicais não pode ser apropriadamente compreendida sem levar a antártica em consideração. O Oceano Austral influencia as correntes marítimas e o clima de todos os outros oceanos da terra, além de ter papel fundamental no balanço de $\mathrm{CO}_{2}$ do planeta.

10 JONES, Anna. Global Relevance of Antartic Science. Apresentação na XXVI ATCM, Madri, 2003. Disponível em <HTTP://www.scar.org/articles>.

11 Retirado do sítio

http://360graus.terra.com.br/ecologia/default.asp?did=26853\&action=reportagem $>$

Em 14.11.2010. 
Artigo original

Hegemonia - Revista Eletrônica de Relações Internacionais do Centro Universitário Unieuro

ISSN: $1809-1261$

UNIEURO, Brasília, número 10, 2012, pp. 92-126.

Foram pesquisadores polares que alertaram para a existência do buraco da camada de ozônio e confirmaram a hipótese de que este seria causado por clorofluorcarbonetos (CFC) industriais. Assim a discussão sobre mudança do clima esta instrisicamente ligada à Antártica, não só pela importância do manto de gelo para a regulação do clima mundial ou pelos impactos desastrosos que teriam 0 derretimento da calota polar. Devemos isso em boa parte à cooperação científica que existe no âmbito do Tratado da Antártica.

A realização da pesquisa científica na Antártica só é possível graças à cooperação internacional proporcionada pelo STA. Ao entrar no SCAR, qualquer nação passa a ter acesso a uma gigantesca base de dados já consolidada, possibilitando que os programas nacionais não comecem do zero, e disponibilizando décadas de dados comparativos. Isso seria impensável fora do quadro de cooperação internacional, sem coordenação e cooperação, os programas nacionais antárticos jamais produziriam o mesmo volume de dados disponíveis pelo SCAR e dificilmente hoje teríamos como avaliar fenômenos climáticos globais de forma apropriada. 
Artigo original

Hegemonia - Revista Eletrônica de Relações Internacionais do Centro Universitário Unieuro

ISSN: $1809-1261$

UNIEURO, Brasília, número 10, 2012, pp. 92-126.

TRATADOS DE COOPERAÇÃO NA ANTÁRTICA SOBRE O MEIO AMBIENTE

A exploração dos recursos naturais foi abordada em três convenções separadas, sem perder de vista o "uso racional" dos recursos: a Convenção para Conservação das Focas Antárticas, (CCAS); a Convenção para Conservação dos Recursos Marinhos Vivos da Antártica, (CCAMLR)12; e a Convenção para regulamentação de Atividades sobre Recursos Minerais Antárticos, (CRAMRA). ${ }^{13}$ Em 1991, foi adotado o Protocolo sobre Proteção Ambiental do Tratado da Antártica, o Protocolo de Madri, que baniu por 50 anos as atividades minerais e consolidou o viés ambientalista já presente nas ATCMs $^{14}$ como o princípio condutor das atividades humanas na Antártica.

Desses Tratados, o protocolo de Madri é o mais notório, ele suplementa o Tratado da Antártica, declarando a área ao sul de paralelo $60^{\circ} \mathrm{S}^{15}$ "reserva natural, dedicada à paz e à ciência" (Art.II). O protocolo exorta os países contratantes a cooperar na implementação das medidas necessárias ao cumprimento de suas

\footnotetext{
12 Pronuncia-se "camelar".

13 Para informações adicionais ver FERREIRA 2009.

14 ATCM é Reunião Consultiva do Tratado da Antártica.

15 VER anexo MAPAS: B).
} 
Artigo original

Hegemonia - Revista Eletrônica de Relações Internacionais do Centro Universitário Unieuro

ISSN: $1809-1261$

UNIEURO, Brasília, número 10, 2012, pp. 92-126.

provisões (Art. VI) e a cumprir as obrigações decorrentes de outros instrumentos do STA de forma consistente com os termos do Protocolo (Art. V). Para garantir a efetividade de suas medidas, o Protocolo estabelece um mecanismo de inspeções - na prática, as inspeções no âmbito do Tratado da Antártica passaram a também verificar o cumprimento das Medidas do Protocolo. Adiante o Art. VII proíbe "qualquer atividade relacionada a recursos minerais, salvo pesquisas cientificas", por tempo indefinido, enquanto o protocolo estiver em vigor, em $2048^{16}$, portanto.

Os seis anexos do protocolo especificam normas de proteção ambiental. Os anexos correspondem em grande medida a recomendações aprovadas ao longo das ATCMs, antes espalhadas em um emaranhado de regras desarticuladas, agora integradas em um instrumento jurídico mais forte. O protocolo cria então mais uma instância no STA, o Comitê para proteção ambiental (Committee for Environmental Protection, CEP), do qual fazem parte todas as Partes do Protocolo.

O CEP é análogo ao SCAR, enquanto este coordena a pesquisa cientifica, a função daquele é de lidar com questões ambientais. 
Artigo original

Hegemonia - Revista Eletrônica de Relações Internacionais do Centro Universitário Unieuro

ISSN: $1809-1261$

UNIEURO, Brasília, número 10, 2012, pp. 92-126.

Ferreira ainda expõe que apesar de ser um fórum consultivo com poucos anos de funcionamento, sua efetividade pode ser medida com a adoção pelas ATCMs de suas recomendações. É presumível que o CEP venha a ter um papel crescente no STA e que, a exemplo do SCAR, tenha impacto determinante na formulação da agenda e nos condicionantes para as decisões das Partes Consultivas.

O protocolo de Madri não pode ser considerado uma inovação, dado que suas normas derivam de recomendações da ATCMs. No entanto, é obviamente um avanço grande em matéria de proteção ambiental.

\section{O FUTURO DO TRATADO DA ANTÁRTICA}

A possibilidade de ampla revisão do regime a partir de 1991 levou muitos trabalhos especular amplamente sobre o futuro do STA. O ano de 1991 passou, e nenhuma das Partes Consultivas solicitou a revisão do regime e aparentemente essa possibilidade nem chegou a ser cogitada seriamente. Pelo contrario, desde 1991 assistimos à expansão e ao fortalecimento do STA, com novas adesões, uma maior formalização do regime e o fim dos questionamentos ao Tratado no âmbito das Nações Unidas. Com a proximidade dos 50 anos da entrada em vigor do Tratado, em 2011, podemos retornar 
Artigo original

Hegemonia - Revista Eletrônica de Relações Internacionais do Centro Universitário Unieuro

ISSN: $1809-1261$

UNIEURO, Brasília, número 10, 2012, pp. 92-126.

esse questionamento, mas não mais com o objetivo de especular sobre a revisão do regime. ${ }^{17}$

O atual número de adesões e de Partes Consultivas torna imprevisível o resultado de uma hipotética conferência de revisão, onde as decisões seriam tomadas por maioria simples dos países membros (desde que incluída a maioria das Partes Consultivas). Os países territorialistas veriam-se em minoria absoluta, e não se saberia quais seriam os ganhos reais para um país não territorialista, dessa revisão, que garantiria pleno acesso ao continente e à regulação de seus recursos.

Outro fator que é sempre apontado como fator de instabilidade na Antártica que é a questão da exploração de recursos minerais, parece esta controlada, pelo menos até 2048 , ano no qual o Protocolo de Madri poderá ser revisto. Há ainda quem alerte que o recurso mais abundante do continente, os gelos das calotas polares ( $80 \%$ da água doce do planeta), passe a ser objeto de disputa diante das previsões de esgotamento das fontes de água potável do mundo no futuro. Para essa questão já foi considerada até a possibilidade de rebocar pequenos icebergs (pequenos para os padrões antárticos) em

17 FERREIRA, 2009, P.111. 
Artigo original

Hegemonia - Revista Eletrônica de Relações Internacionais do Centro Universitário Unieuro

ISSN: $1809-1261$

UNIEURO, Brasília, número 10, 2012, pp. 92-126.

situação de crise de abastecimento d'água para regiões secas do hemisfério sul. Porém não parece muito clara a viabilidade econômica de coletar gelo antártico e transportá-lo por milhares e milhares de quilômetros em comparação a iniciativas para um uso mais racional dos recursos existentes ou ao desenvolvimento de tecnologias de dessalinização da água do mar. ${ }^{18}$

Salvo algum fator extraordinário- como um conflito de grandes proporções envolvendo duas ou mais Partes Consultivas, por exemplo- o mais provável é que o STA siga o padrão mantido até agora: permanente negociação, cooperação cientifica e preocupação ambiental. Qualquer modificação que ocorra no regime internacional que administra a Antártica provavelmente será feita a partir da estrutura do Tratado- e isso será mais uma evolução, não uma revolução.

\section{CONCLUSÃO}

Na primeira parte desse artigo foram abordadas as primeiras formas de cooperação que ocorreram no continente antártico. Num como um bem de luxo, mas nesse caso sua exploração seria, por definição, restrita. 
Artigo original

Hegemonia - Revista Eletrônica de Relações Internacionais do Centro Universitário Unieuro

ISSN: $1809-1261$

UNIEURO, Brasília, número 10, 2012, pp. 92-126.

primeiro momento elas surgiram para resolver a questão territorial, pois sete países reivindicavam soberania sobre o local. Resolvida essa questão -não tão bem resolvida, mas pelo menos acordada de forma pacífica- surgiram às primeiras preocupações com o que o continente tinha de mais abundante e ate aquele momento, intocado, o seu meio ambiente, fauna e flora. Cientistas observaram que o espaço geofísico da terra antártica era perfeito para estudos científicos, nascendo assim à primeira forma de cooperação internacional no local, o AGI (Ano Geofísico Internacional).

A cooperação cientifica se mostrou a chave para a solução de problemas no local, e o maior exemplo a ser citado é o Tratado da Antártica. Que foi abordado no item II desse artigo. Depois da AGI, os participante do mesmo resolveram que deveria ser dado continuidade ao clima de cooperação, nascendo assim o STA. Esse por sua vez apresentou a particularidade de ter sido o primeiro acordo internacional a considerar temas inéditos a sua época, sendo por isso classificado como primeira zona de paz do mundo, primeiro laboratório cientifico aberto a humanidade, primeira reserva ecológica mundial e primeira área desnuclearizada. 
Artigo original

Hegemonia - Revista Eletrônica de Relações Internacionais do Centro Universitário Unieuro

ISSN: $1809-1261$

UNIEURO, Brasília, número 10, 2012, pp. 92-126.

O artigo ainda aborda a importância dos recursos naturais do continente, como a sua posição geográfica ofereceu condições para pesquisa que não foram encontradas em nenhum outro lugar do planeta. Observou-se também como os estudo que são realizados no local contribuem e influenciam de forma sistêmica para acontecimentos atuais, como mudanças climáticas ou alertas sobre possíveis fenômenos da natureza.

Logo depois são mostradas as formas de cooperação sobre meio ambiente no local, sendo a cooperação mais notória o Tratado de Madri. Ele complementa o STA, e na pratica inspeciona o cumprimento das medidas colocadas pelo protocolo. Os seis anexos do seu do Protocolo de Madri especificam sobre proteção ambiental, ele não pode ser considerado uma inovação, mas de certo é um grande avanço em matéria de proteção ambiental.

E por ultimo foi abordado algumas considerações finais sobre o futuro do tratado, que a preocupação que existia sobre solicitação da revisão do regime nem foi cogitada, e que se caso ocorre-se ninguém sairia completamente satisfeito. E que o tratado só será modificado caso ocorra algo de bastante relevância no cenário internacional. 
Artigo original

Hegemonia - Revista Eletrônica de Relações Internacionais do Centro Universitário Unieuro

ISSN: $1809-1261$

UNIEURO, Brasília, número 10, 2012, pp. 92-126.

O objetivo do artigo foi tentar explicar mais sobre um continente muito importante para a história mundial atual. Infelizmente não é do conhecimento de todos, o qual vital a Antártica é para a sociedade atualmente, o que é uma pena, a área é considerada um bem comum da humanidade, portanto, sendo do interesse de todos conhecê-la melhor. O bem mais valioso da antártica provou ser nesses últimos 50 anos a sua importância ambiental e cientifica claro que isso não o livra de futuras crises pela exploração de recursos naturais que possam vir a abalar seu funcionamento. Porém, caso aconteça, o mais provável é que essas crises do futuro venham a ser resolvidas como foram nessas últimas cinco décadas, com soluções endógenas acordadas nos termos do STA e não com rupturas.

\section{PÓS-DATA, MARÇO DE 2012.}

No dia 25 de fevereiro de 2012, pela madrugada, ocorreu um incêndio na base brasileira da Antártica, a estação Comandante Ferraz. O incêndio começou na casa das máquinas, no local onde ficam os geradores que fornecem energia à estação. $O$ acidente deixou dois militares mortos e $70 \%$ da base de pesquisa destruídos, 
Artigo original

Hegemonia - Revista Eletrônica de Relações Internacionais do Centro Universitário Unieuro

ISSN: $1809-1261$

UNIEURO, Brasília, número 10, 2012, pp. 92-126.

segundo dados do chefe da estação que retornou à base para uma avaliação preliminar.

O prédio principal da base, onde ficavam a parte habitável e alguns laboratórios de pesquisas, foi completamente atingido pelo incêndio, tendo permanecidos intactos os refúgios (módulos isolados para casos de emergência), os laboratórios (de meteorologia, de química e de estudo da alta atmosfera), os tanques de combustíveis e o heliponto da estação, que são estruturas isoladas do prédio principal.

De acordo com a avaliação do professor e diretor do Centro Polar e Climático da Universidade Federal do Rio Grande do Sul, Jefferson Simões, que já esteve 19 vezes no continente gelado, das quais cinco na Comandante Ferraz, o incêndio que destruiu a Estação comprometeu $40 \%$ do programa antártico brasileiro. O professor Simões ainda afirma que o incêndio não paralisou totalmente as pesquisas, e a preocupação agora é de se manter os trabalhos que não foram afetados: "grande parte dos dados referentes às pesquisas está no Brasil e continuarão a ser estudados". De fato os conhecimentos adquiridos nas pesquisas no continente Antártico fazem parte de um eixo estratégico brasileiro que não deve ser perdido.

Dia 6 de março de 2012, foram chamados para debater sobre o acidente e planos futuros no Senado Federal, os ministros da Defesa e de Ciência, Tecnologia e Inovação, Celso Amorin e Marco Antonio Raupp, respectivamente. O ministro Amorim, informou aos senadores, que a construção de uma nova base científica na Antártica 
Artigo original

Hegemonia - Revista Eletrônica de Relações Internacionais do Centro Universitário Unieuro

ISSN: $1809-1261$

UNIEURO, Brasília, número 10, 2012, pp. 92-126.

só deve começar no verão de 2013/2014 devido à impossibilidade de ocorrer durantes o inverno, onde as temperaturas podem atingir até $30^{\circ}$. Porém, a retomada das pesquisas do Programa Antártico Brasileiro- Proantar- será feita imediatamente e o governo pretende, ainda, intensificar a cooperação internacional para uso de bases de outros países na Antártica.

Durante a realização da discussão no Senado as autoridades destacaram que é importante atrelar as atividades de reconstrução da estação brasileira na Antártica às ações do Plano Plurianual (PPA). Apesar de não divulgarem valores exatos, o custo médio de uma estação moderna e de porte razoável é de cerca de $\mathrm{R} \$ 100$ milhões. A nova base oferecerá condições melhores e mais modernas para que os pesquisadores atuem no local. Explicaram ainda que em 2012 serão elaborados o pré-projeto da nova base e em seguida o projeto detalhado, que vão levar em conta as experiências recentes de outros países, como a da Espanha e a da Coréia do Sul. O projeto detalhado deverá ser submetido aos países-membros do Tratado da Antártica, e só após a concordância dos signatários do tradado que a reconstrução da base poderá começar.

As principais linhas de pesquisa desenvolvidas lá tratam de biologia marinha, de monitoramento ambiental e da camada de ozônio. Ainda é cedo para qualquer especulação sobre o acidente. A Marinha está com Inquérito Policial Militar (IPM) aberto tem 40 dias, prorrogáveis por mais 20 para concluir a investigação. O grupo faz ainda avaliação do local, observando condições de habitabilidade e avaliação ambiental. 
Artigo original

Hegemonia - Revista Eletrônica de Relações Internacionais do Centro Universitário Unieuro

ISSN: $1809-1261$

UNIEURO, Brasília, número 10, 2012, pp. 92-126.

\section{REFERÊNCIAS BIBLIOGRÁFICAS}

- AZAMBUjA, Pericles. Antártida: História e Geopolítica.Porto Alegre; CORAG, 1981.

- BARGAGLI, Roberto. Antartic Ecosystems: Environmental Contamination, Climate Change and Human Impact. Berlim; Springer-Verlag, 2005.

- FERREIRA, Felipe Rodrigues Gomes. O sistema do Tratado da Antártica: Evolução do Regime e seu Impacto na Política Externa Brasileira. Brasília; Fundação Alexandre Gusmão, 2009.

- MELLO, Celso D.de Alburqueque. Curso de Direito Internacional Público. V.II. Rio de Janeiro; Renovar, 2004.

- SILVA, Maria Cristina Lima Ribeiro. Contribuição ao estudo da Antártica no sistema de Relações Internacionais. São Paulo, 1987. Dissertação (Mestrado em Direito) - Faculdade de Direito da USP.

\section{Sítos:}

$<$ http://www.ecoterrabrasil.com.br/home/index.php?pg=temas\&tipo=tema $\underline{s \& c d=465>}$

<http://www.portalsaofrancisco.com.br/alfa/antartidacontinente/antartida-7.php> 
Artigo original

Hegemonia - Revista Eletrônica de Relações Internacionais do Centro Universitário Unieuro

ISSN: $1809-1261$

UNIEURO, Brasília, número 10, 2012, pp. 92-126.

<http://www.ats.aq/e/ats_treaty.htm>

<http://ultimaparada.wordpress.com/category/antartida >

$<$ http://memoria.cnpq.br/areas/terra meioambiente/proantar/index.htm $>$

$<\underline{\text { http://www.falke.com.br/sistema.htm }>}$

http://www.jb.com.br/pais/noticias/2012/02/26/incendio-comprometeu-40do-programa-antartico-brasileiro-diz-pesquisador-2/. Acesso em $06 / 03 / 2012$

http://ciencia.hsw.uol.com.br/estacao-comandante-ferraz.htm

http://www1.folha.uol.com.br/poder/1056261-senado-ouvira-amorimsobre-acidente-na-base-na-antartida.shtml . Acesso em 06/03/2012

http://www12.senado.gov.br/noticias/materias/2012/02/28/comissoes-vaodebater-acidente-na-antartica . Acesso em 10/03/2012

http://www12.senado.gov.br/noticias/materias/2012/03/06/brasil-querintensificar-cooperacao-internacional-para-uso-de-bases-de-outros-paisesna-antartica . Acesso em 10/03/2012

http://www12.senado.gov.br/noticias/materias/2012/03/06/ministrosexplicam-plano-de-recuperacao-de-estacao-na-antartica . Acesso em $10 / 03 / 2012$

http://www12.senado.gov.br/noticias/materias/2012/03/06/nova-base-naantartica-deve-comecar-a-ser-construida-no-fim-de-2013-informa-ministro - Acesso em 10/03/2012

https://www.mar.mil.br/secirm/proantar.htm\#estacao . Acesso em $10 / 03 / 2012$

http://www12.senado.gov.br/noticias/materias/2012/03/06/causas-datragedia-na-antartica-estao-sendo-investigadas-diz-celso-amorim Acesso em $10 / 03 / 2012$ 
Artigo original

Hegemonia - Revista Eletrônica de Relações Internacionais do Centro Universitário Unieuro

ISSN: 1809-1261

UNIEURO, Brasília, número 10, 2012, pp. 92-126.

http://www.jb.com.br/pais/noticias/2012/03/06/reconstrucao-de-novabase-na-antartica-esta-estimada-em-r-100-milhoes/ Acesso em $10 / 03 / 2012$

\section{Anexos}

TRATADO DA ANTÁRTIDA (1959)

Os Governos da Argentina, Austrália, Bélgica, Chile, República Francesa, Nova Zelândia, Noruega, União da África do Sul, União das Repúblicas Socialistas Soviéticas, Reino Unido da Grã-Bretanha e Irlanda do Norte, e Estados Unidos da América.

Reconhecendo ser de interesse de toda a humanidade que a Antártida continue para sempre a ser utilizada exclusivamente para fins pacíficos e não se converta em cenárioou objeto de discórdias internacionais;

Reconhecendo as importantes contribuições dos conhecimentos científicos logrados através da colaboração internacional na pesquisa científica realizada na Antártida;

Convecidos de que o estabelecimento de uma firme base para o prosseguimento e desenvolvimento de tal colaboração com lastro na liberdade de pesquisa científica na Antártida, conforme ocorreu durante o Ano Geofísico Internacional, está de acordo com os interesses da ciência e com progresso de toda a humanidade;

Convencidos, também, de que um tratado que assegure a utilização da Antártida somente para fins pacíficos e de que o prosseguimento da harmonia internacional na Antártida fortalecerão os fins e princípios corporificados na Carta das Nações Unidas;

Concordam no seguinte: 
Artigo original

Hegemonia - Revista Eletrônica de Relações Internacionais do Centro Universitário Unieuro

ISSN: 1809-1261

UNIEURO, Brasília, número 10, 2012, pp. 92-126.

\section{ARTIGO I}

1. A Antártida será utilizada somente para fins pacíficos. Serão proibidas, inter alia, quaisquer medidas de natureza militar, tais como o estabelecimento de bases e fortificações, a realização de manobras militares, assim como as experiências com quaisquer tipos de armas.

2. O presente Tratado não impedirá a utilização de pessoal ou equipamento militar para pesquisa científica ou para qualquer outro propósito pacífico.

\section{ARTIGO II}

Persistirá, sujeita às disposições do presente Tratado, a liberdade de pequisa científica na Antártida e de colaboração para este fim, conforme exercida durante o Ano Geofísico Internacional.

\section{ARTIGO III}

1. A fim de promover a cooperação internacional para a pesquisa científica na Antártida, como previsto no Artigo II do presente Tratado, as Partes Contratantes concordam, sempre que possível e praticável, em que:

a) a informação relativa a planos para programas científicos, na Antártida, será permutada a fim de permitir a máxima economia e eficiência das operações; b) o pessoal científico na Antártida, será permutado entre expedições e estações;

c) as observações e resultados científicos obtidos na Antártida serão permutados e tornados livremente utilizáveis.

2. Na implementação deste artigo, será dado todo o estímulo ao estabelecimento de relações de trabalho cooperativo com as agências especializadas das Nações Unidas e com outras organizações internacionais que tenham interesse científico ou técnico na Antártida. 
Artigo original

Hegemonia - Revista Eletrônica de Relações Internacionais do Centro Universitário Unieuro

ISSN: 1809-1261

UNIEURO, Brasília, número 10, 2012, pp. 92-126.

1. Nada que se contenha no presente Tratado poderá ser interpretado como:

a) renúncia, por quaisquer das Partes Contratantes, a direitos previamente invocados ou a pretensões de soberania territorial na Antártida;

b) renúncia ou diminuição, por quaisquer das Partes Contratantes, a qualquer base de reivindicação de soberania territorial na Antártida que possa ter, quer como resultado de suas atividades, ou de seus nacionais, na Antártida, quer por qualquer outra forma;

c) prejulgamento da posição de qualquer das Partes Contratantes quanto ao reconhecimento dos direitos ou reinvidicações ou bases de reivindicação de algum outro Estado quanto à soberania territorial na Antártida.

2. Nenhum ato ou atividade que tenha lugar, enquanto vigorar o presente Tratado, constituirá base para programar, apoiar ou contestar reivindicação sobre soberania territorial na Antártida, ou para criar direitos de soberania na Antártida. Nenhuma nova reinvindicação, ou ampliação de reinvindicação existente, relativa à soberania territorial na Antártida será apresentada enquanto o presente Tratado estiver em vigor.

\section{ARTIGO V}

1. Ficam proibidas as explosões nucleares na Antártida, bem como o lançamento ali de lixo ou resíduos radioativos.

2. No caso da conclusão de acordos internacionais sobre a utilização da energia nuclear inclusive as explosões nucleares e o lançamento de resíduos radioativos, de que participem todas as Partes Contratantes, cujos representantes estejam habilitados a participar das reuniões previstas no Artigo X, aplicar-se-ão à Antártida as regras estabelecidas em tais acordos.

\section{ARTIGO VI}

As disposições do presente Tratado apliar-se-ão à área situada ao sul de 60 graus de latitude sul, inclusive às plataformas de gelo, porém 
Artigo original

Hegemonia - Revista Eletrônica de Relações Internacionais do Centro Universitário Unieuro

ISSN: $1809-1261$

UNIEURO, Brasília, número 10, 2012, pp. 92-126.

nada no presente Tratado prejudicará e, de forma alguma, poderá alterar os direitos ou exercícios dos direitos, de qualquer Estado, de acordo com o direito internacional aplicável ao alto-mar, dentro daquela área.

\section{ARTIGO VII}

1. A fim de promover os objetivos e assegurar a observância das disposições do presente Tratado, cada Parte Contratante, cujos representantes estiverem habilitados a participar das reuniões previstas no Artigo IX, terá o direito de designar observadores para realizarem os trabalhos de inspenção previstos no presente artigo. Os obseradores deverão ser nacionais das Partes Contratantes que os designarem. Os nomes dos observadores serão comunicados a todas as outras Partes Contratantes, que tenham o direito de designar observadores e idênticas comunicações serão feitas ao terminarem sua missão.

2. Cada observador, designado de acordo com as disposições do Parágrafo 1 deste artigo, terá completa liberdade de acesso, em qualquer tempo a qualquer e a todas as áreas da Antártida.

3. Todas as áreas da Antártida, inclusive todas as estações, instalações e equipamentos existentes nestas áreas, e todos os navios e aeronaves em pontos de embarque ou desembarque na Antártida estarão a todo tempo abertos à inspenção de quaisquer observadores designados de acordo com o parágrafo 1 deste artigo.

4. A observação aérea poderá ser efetuada a qualquer tempo, sobre qualquer das áreas da Antártida, por qualquer das Partes Contratantes que tenha o direito de designar observadores.

5. Cada Parte Contratante no momento em que este Tratado entrar em vigor, informará as outras Partes Contratantes e daí por diante darão noticia antecipada de:

a) todas as expedições com destino à Antártida, por parte de seus navios ou nacionais, e todas as expedições à Antártida organizadas em seu território ou procedentes do mesmo; 
Artigo original

Hegemonia - Revista Eletrônica de Relações Internacionais do Centro Universitário Unieuro

ISSN: $1809-1261$

UNIEURO, Brasília, número 10, 2012, pp. 92-126.

b) todas as estações antártida que estejam ocupadas por súditos de sua nacionalidade;

$E$

c) todo o pessoal ou equipamento militar que um país pretenda introduzir na Antártida, observadas as condições previstas no Parágrafo 2 do Artigo I do presente Tratado.

\section{ARTIGO VIII}

1. A fim de facilitar o exercício de suas funções, de conformidade com o presente Tratado, e sem prejuízo das respectivas posições das Partes Contratantes relativamente à jurisdição sobre todas as pessoas na Antártida, os observadores designados de acordo com o Parágrafo 1 do Artigo VII, e o pessoal científico intercambiado de acordo com o subparágrafo 1(b) do Artigo III deste Tratado, e os auxiliares que acompanhem as referidas pessoas, serão sujeitos apenas à jurisdição da Parte Contratante de que sejam nacionais, a respeito de todos os atos ou omissões que realizarem, enquanto permaneceram na Antártida, relacionados com o cumprimento de suas funções.

2. Sem prejuízo das disposições do Parágrafo 1 deste artigo, e até que sejam adotadas as medidas previstas no subparágrafo 1 (e) do Artigo IX, as Partes Contratantes interessadas em qualquer caso de litígio, a respeito do exercício de jurisdição na Antártida, deverão consultar-se conjuntamente com o fim de alcançarem uma solução mutuamente aceitável.

\section{ARTIGO IX}

1. Os representantes das Partes Contratantes, mencionadas no preâmbulo deste Tratado, reunir-se-ão na cidade de Camberra, dentro de dois meses após a entrada em vigor do Tratado, e daí por diante sucessivamente em datas e lugares convenientes, para 0 propósito de intercambiarem informações, consultarem-se sobre matéria de interesse comum pertinente à Antártida e formularem, considerarem e recomendarem a seus Governos medidas concretizadoras dos princípios e objetivos do Tratado, inclusive as normas relativas ao: 
Artigo original

Hegemonia - Revista Eletrônica de Relações Internacionais do Centro Universitário Unieuro

ISSN: $1809-1261$

UNIEURO, Brasília, número 10, 2012, pp. 92-126.

a) uso da Antártida somente para fins pacíficos

b) facilitação de pesquisas científicas na Antártida;

c) facilitação da cooperação internacional da Antártida;

d) facilitação do exercício do direito de inspenção previsto no Artigo VII do Tratado;

e) questões relativas ao exercício de jurisdição na Antártida;

f) preservação e conservação dos recursos vivos na Antártida.

2. Cada Parte Contratante que se tiver tornado membro deste Tratado por adesão, de acordo com o Artigo XIII, estará habilitada a designar representantes para comparecerem às reuniões referidas no Parágrafo 1 do presente artigo, durante todo o tempo em que a referida Parte Contratante demonstrar seu interesse pela Antártida, pela promoção ali de substancial atividade de pesquisa científica, tal como o estabelecimento de estação científica ou o envio de expedição científica.

3. Os relatórios dos observadores referidos no Artigo VII do presente Tratado deverá ser transmitidos aos representantes das Partes Contratantes que participarem das reuniões previstas no Parágrafo 1 do presente artigo.

4. As medidas previstas no Parágrafo 1 deste artigo tornar-se-ão efetivas quando aprovadas por todas as Partes Contratantes, cujos representantes estiverem autorizados a participar das reuniões em que sejam estudadas tais medidas.

5. Todo e qualquer direito estabelecido no presente Tratado poderá ser exercido a partir da data em que o Tratado entrar em vigor, tenham ou não sido propostos, considerados, ou aprovados, 
Artigo original

Hegemonia - Revista Eletrônica de Relações Internacionais do Centro Universitário Unieuro

ISSN: $1809-1261$

UNIEURO, Brasília, número 10, 2012, pp. 92-126.

conforme as disposições deste Artigo, as medidas destinadas a facilitar o exercício de tais direitos.

\section{ARTIGO X}

Cada umas das Partes Contratantes compromete-se a empregar os esforços apropriados, de conformidade com a Carta das Nações Unidas, para que ninguém exerça na Antártida qualquer atividade contrária aos princípios e propósitos do presente Tratado.

\section{ARTIGO XI}

1. Se surgir qualquer controvérsia entre duas ou mais das Partes Contratantes, a respeito da interpretação ou aplicação do presente Tratado, estas Partes Contratantes se consultarão entre si para que o dissídio se resolva por negociação, investigação, conciliação, arbitramente, decisão judicial ou outro meio pacífico de sua escolha.

2. Qualquer controvérsia dessa natureza, que não possa ser resolvida por aqueles meios, será levada à Corte Internacional de Justiça, com o consentimento, em cada caso, de todas as Partes interessadas. Porém se não for obtido um consenso a respeito do encaminhamento da controvérsia à Corte Internacional, as Partes em litígio não se eximirão da responsabilidade de continuar a procurar resolvê-la por qualquer dos vários meios pacíficos referidos no Parágrafo 1 deste artigo.

\section{ARTIGO XII}

1. a) O presente Tratado pode ser modificado ou emendado em qualquer tempo, por acordo unânime das Partes Contratantes cujos representantes estiverem habilitados a participar das reuniões previstas no Artigo IX. Qualquer modificação ou emenda entrará em vigor quando o Governo depositário tiver recebido comunicação, de todas as Partes Contrantes, de a haverem ratificado.

b) Tal modificação ou emenda, daí por diante, entrará em vigor em relação a qualque outra Parte Contratante quando o Governo depositário receber notícia de sua ratificação. Qualquer Parte Contratante de que não se tenha notícia de haver 
Artigo original

Hegemonia - Revista Eletrônica de Relações Internacionais do Centro Universitário Unieuro

ISSN: $1809-1261$

UNIEURO, Brasília, número 10, 2012, pp. 92-126.

ratificado, dentro de dois anos a partir da data da vigência da modificação ou emenda, de acordo com a disposição do Subparágrafo $1(\mathrm{a})$ deste artigo, será considerada como se tendo retirado do presente Tratado na data da expiração daquele prazo.

2.a) Se, depois de decorridos trinta anos da data da vigência do presente Tratado, qualquer das Partes Contratantes, cujos representantes estiverem habilitados a participar das reuniões previstas no Artigo IX, assim o requerer, em comunicação dirigida ao Governo depositário, uma conferência de todas as Partes Contratantes será realizada logo que seja praticável para rever o funcionamento do Tratado. b) Qualquer modificação ou emenda ao presente Tratado, que for aprovada em tal conferência pela maioria das Partes Contratantes nela representadas, inclusive a maioria daquelas cujos representantes estão habilitados a participar das reuniões previstas no Artigo IX, será comunicada pelo Governo depositário a todas as Partes Contratantes imediatamente após o término da conferência e entrará em vigor de acordo com as disposições do Parágrafo 1 do presente artigo.

c) Se qualquer modificação ou emenda não tiver entrado em vigor, de acordo com as disposições do Subparágrafo 1(a) deste artigo, dentro do período de dois anos após a data de sua comunicação a todas as Partes Contratantes, qualquer tempo após a expiração daquele prazo, comunicar ao Governo depositário sua retirada do presente Tratado e esta retirada terá efeito dois anos após o recebimento da comunicação pelo Governo depositário.

\section{ARTIGO XIII}

1. O presente Tratado estará sujeito à ratificação por todos os Estados signatários. Ficará aberto à adesão de qualquer Estado que for membro das Nações Unidas, ou de qualquer outro Estado que possa ser convidado a aderir ao Tratado com o consentimento de todas as Partes Contratantes cujos representantes estiverem habilitados a participar das reuniões previstas ao Artigo IX do Tratado.

2. A ratificação ou a adesão ao presente Tratado será efetuada por cada Estado de acordo com os seus processos constitucionais. 
Artigo original

Hegemonia - Revista Eletrônica de Relações Internacionais do Centro Universitário Unieuro

ISSN: $1809-1261$

UNIEURO, Brasília, número 10, 2012, pp. 92-126.

3. Os instrumentos de ratificação ou de adesão estão depositados junto ao Governo dos Estados Unidos da América, aqui designado Governo depositário.

4. O Governo depositário informará todos os Estados signatários e dos aderentes, da data de cada depósito de instrumento de ratificação ou adesão e da data de entrada em vigor do Tratado ou de qualquer emenda ou modificação.

5. Feito o depósito dos instrumentos de ratificação por todos os Estados signatários, o presente Tratado entrará em vigor para qualquer Estado aderente na data do depósito do instrumento de adesão.

6. O presente Tratado será registrado pelo Governo depositário, de conformidade com o Artigo 102 da Carta das Nações Unidas.

\section{ARTIGO XIV}

O presente Tratado, feito nas línguas inglesa, francesa, russa e espanhola, em versões igualmente idênticas, será depositado nos arquivos do Governo dos Estados Unidos da América, que enviará cópias aos Governos dos Estados signatários e aderentes.

\section{Antártica}


Artigo original

Hegemonia - Revista Eletrônica de Relações Internacionais do Centro Universitário Unieuro

ISSN: $1809-1261$

UNIEURO, Brasília, número 10, 2012, pp. 92-126.

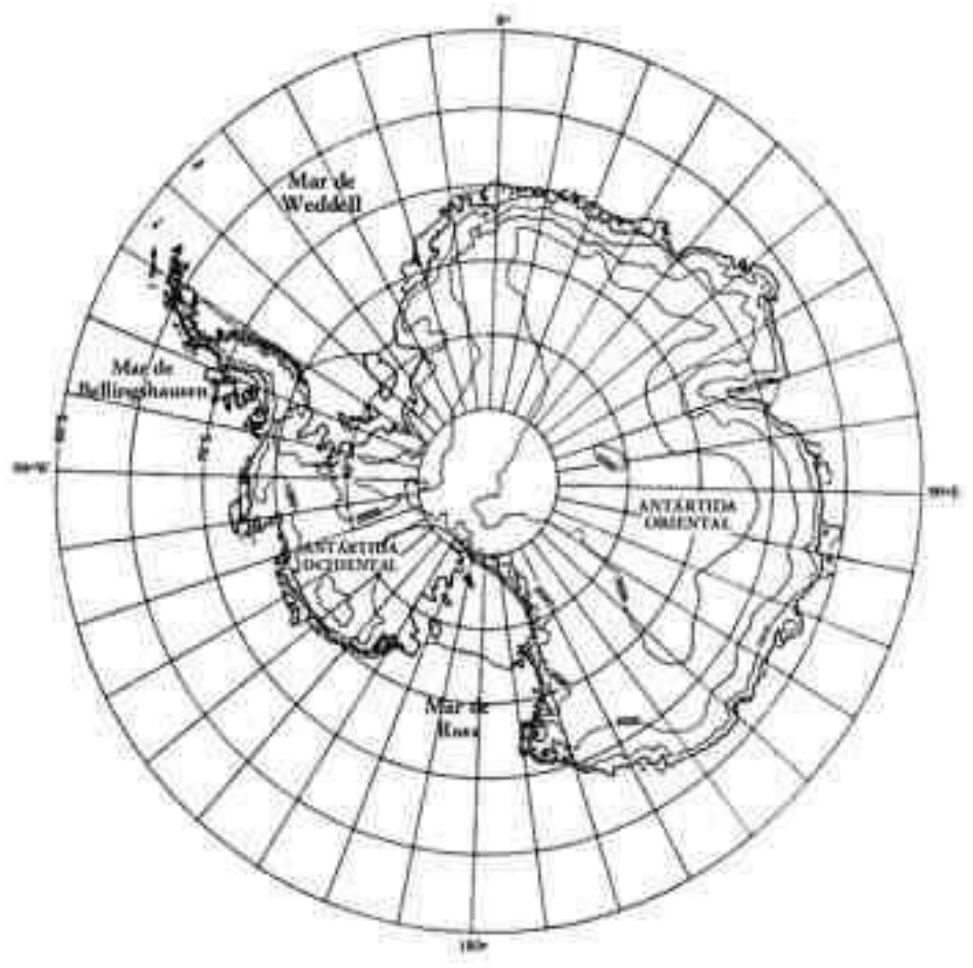

Península Antártica e Ilha Rei George. 
Artigo original

Hegemonia - Revista Eletrônica de Relações Internacionais do Centro Universitário Unieuro

ISSN: 1809-1261

UNIEURO, Brasília, número 10, 2012, pp. 92-126.

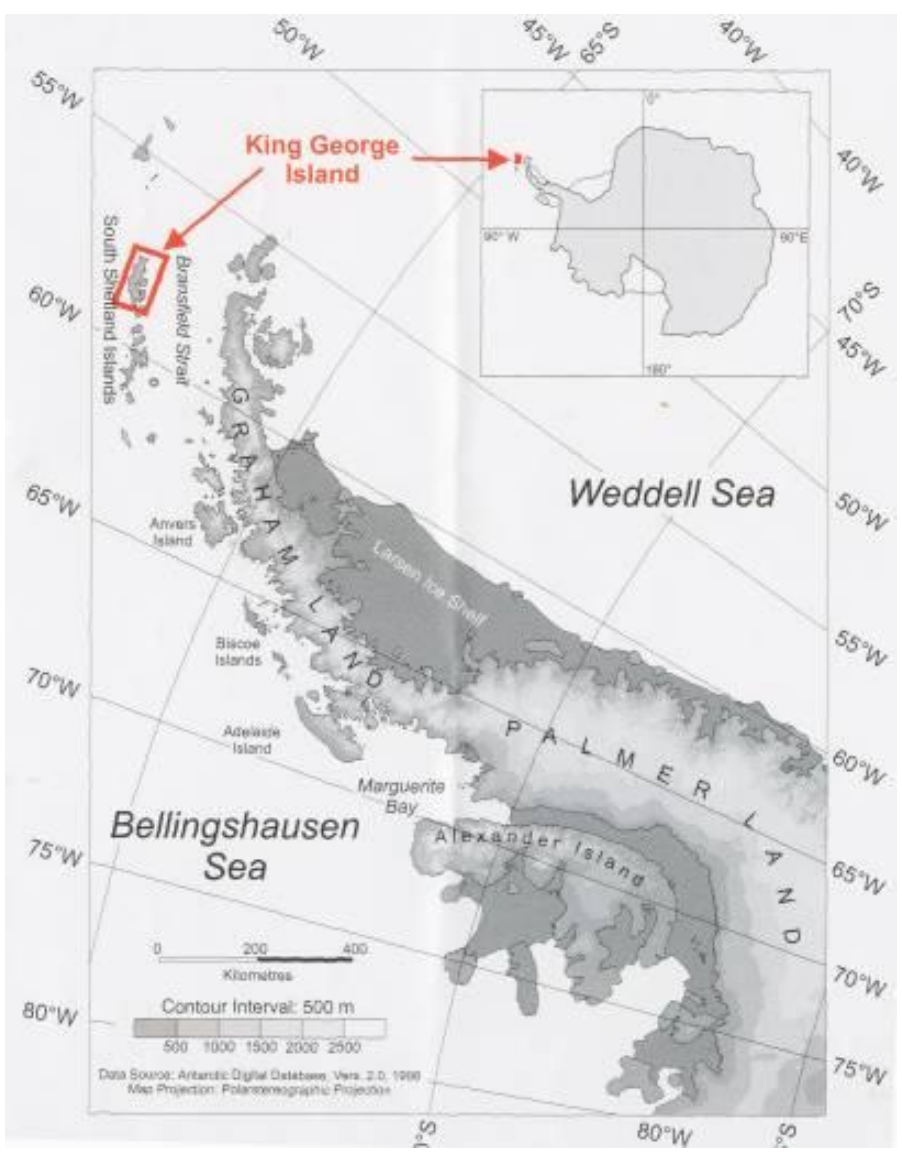

